Meta

Journal des traducteurs

Translators' Journal

\title{
Nine Theses About Anecdotalism in the Study of Translation (With Special Reference to Sherry Simon, Ed., Culture in Transit)
}

\section{Douglas Robinson}

Volume 44, numéro 2, juin 1999

URI : https://id.erudit.org/iderudit/003966ar

DOI : https://doi.org/10.7202/003966ar

Aller au sommaire du numéro

Éditeur(s)

Les Presses de l'Université de Montréal

ISSN

0026-0452 (imprimé)

1492-1421 (numérique)

Découvrir la revue

Citer cet article

Robinson, D. (1999). Nine Theses About Anecdotalism in the Study of Translation (With Special Reference to Sherry Simon, Ed., Culture in Transit).

Meta, 44(2), 402-408. https://doi.org/10.7202/003966ar
Résumé de l'article

Depuis des siècles, la théorie de la traduction comporte un caractère anecdotique qui est parfois critiqué par la traductologie des dernières décennies. L'auteur fait un tour de la question et conclut à la complémentarité des deux types d'approches. 
3. Capo (1990: 6) defines "intellectualisation" as the "ability of (a) language to be used as a means of expressing the most abstract and most modern notions of science, technology, law and philosophy."

\section{REFERENCES}

Antia, Bassey (1990): "Independance and Language Planning: An Investigation of Terminological Strategies in Nigerian Languages", paper presented to the 11th Annual Conference of the Linguistic Association of Nigeria, Calabar, p. 6.

Capo, H.B.C. (1990): “Comparative Linguistics and Language Engineering in Africa", in E. N . Emenanjo (Ed.), Multilingualism, M inority Languages and Language Policy in Nigeria, Agbor, Central Books Ltd. in collaboration with the Linguistic Association of Nigeria.

Cyff er , N. (1977): “Language Planning and Universal Free Primary Education: A Kanuri Example", The Nigerian Language Teacher, vol. 1 no. 1.

Emenanjo, E. N. (Ed.) (1990): Multilingualism, Minority Languages and Language Policy in Nigeria, Agbor, Central Books Ltd. in collaboration with the Linguistic Association of $\mathrm{Ni}$ geria.

- - (1990): "In the tradition of the Majors: Lessons in Language Engineering for the $\mathrm{M} \mathrm{i-}$ nority language", E. N. Emenanjo (Ed.), Multilingualism, M inority Languages and Language Policy in Nigeria, Agbor, Central Books Ltd. in collaboration with the Linguistic Association of Nigeria, p. 89.

Hansfor d, K. J. et al. (n.d.): An Index of Nigerian Languages, no. 5 in the series Studies in Nigerian Languages, Accra, Summer Institute of Linguistic.

Jakobson, Roman (1959): "Linguistic Aspects of Translation", Brower (Ed.), On Translation, Cambridge, Mass., Harvard University Press, p. 234.

Jibril, Munzali (1990): "M inority Languages and Lingua Francas in Nigerian Education", in E. N. Emenanjo (Ed.), Multilingualism, Minority Languages and Language Policy in Nigeria, Agbor, Central Books Ltd. in collaboration with the Linguistic Association of Nigeria, p. 114.

Madugu, I. S. G. (1985): "Nupe Orthography", in A. Banjo (Ed.), Orthographies of Nigerian Languages: M anual III, Lagos, National Language Center, p. 25.

New mar k, Peter (1977): "Communicative and Semantic Translation", Babel, vol. 23 no. 4, p. 175.
Nida, E. and C.R. Taber (1974): The Theory and Practice of Translation, Leiden, Brill, p. 1.

Vinay, J.-P. et Jean Dar bel net (1958): Stylistique comparée du français et de l'anglais, Paris, Didier.

Wil I iamson, Kay (1990): "Development of M inority Languages: Publishing Problems and Prospects", in E.N. Emenanjo (Ed.), M ultilingualism, Minority Languages and Language Policy in Nigeria, Agbor, Central Books Ltd. in collaboration with the Linguistic Association of Nigeria, p. 142.

\section{Nine Theses About Anecdotalism in the Study of Translation (With Special Reference to Sherry Simon, Ed., Culture in Transit)}

\section{RÉSUMÉ}

Depuis des siècles, la théorie de la traduction comporte un caractère anecdotique qui est parfois critiqué par la traductologie des dernières décennies. L'auteur fait un tour de la question et conclut à la complémentarité des deux types d'approches.

\section{ABSTRACT}

For centuries, translation theory has had an anecdotal aspect sometimes criticized by recent translation theorists. This author examines this issue and suggests that there are two approaches which go hand in hand.

1. From its beginnings, translation theory has been insistently anecdotal.

Until the last few decades, in fact, theoretical pronouncements on translation have arisen al most exclusively out of specific translators' engagement with specific texts:

- $\quad$ In 55 B.C.E., Cicero tells us that he grew dissatisfied with the then current pedagogical technique of trying to reword and rephrase Latin authors, and decided instead to reword and rephrase Greek authors in Latin.

- In his 395 C.E. letter to Pammachius, Jerome defines his approach to translation in the context of an attack made on him by Rufinus for "mistranslating" a Greek letter for Epiphanius.

- In the 1170s, Burgundio of Pisa tells the story of growing enamoured of a Greek text by St. John Chrysostom while he was in Constantinople and of paying two scribes to copy it for him so he could take it home and translate it.

- In 1470, William Caxton tells several stories surrounding his translation of Virgil's Aeneid and the problems he faced.

- In 1521 and 1530, respectively, Erasmus and Luther defend their translations of the $\mathrm{New}$ 
Testament, Erasmus into Latin, Luther into German, in response to criticisms from Bible scholars who believe that Jerome's Vulgate is God's word.

- In 1661, Pierre-Daniel Huet writes his De interpretatione in the form of a dialogue among contemporary scholars, and introduces the dialogue by describing his own mentor's encouragement and criticisms of his ideas on translation.

Of course what a list of this sort cannot convey is the sheer number, the thousands upon thousands of translators who have commented on their own work in prefaces and letters. These usually describe the circumstances surrounding the work, the problems solved, and the translators' qualms about the fruit of their labours.

2. The anecdotal tradition in translation studies not only continues with unabated strength today; indeed the field is unofficially policed by what amounts to an anecdotal ethic.

Essay collections like Sherry Simon's Culture in Transit and monographs like Suzanne Jill Levine's The Subversive Scribe consist largely or entirely of anecdotal material by translators writing an engagement with specific texts - these are avidly read by other translators facing similar or parallel situations in their own work. Translation conferences are heavily populated with translators telling their peers about the intricacies of their work: how I translated this or that difficult word or phrase, how satisfied or dissatisfied I am with my solutions, etc.

In addition, no matter their systematic, scientific, and theoretical pronouncements, the credibility of a writer on translation continues to depend on assurances that theorizing rests squarely on the theorist's own practical experience as a translator. Scholars who come to the study of translation from poststructuralist theory - people who have never translated anything but have discovered that Walter Benjamin, M artin Heidegger, Jacques Derrida, and Paul de $M$ an have all written interestingly on translation - are widely regarded with suspicion as interlopers and poachers because translation theory for them is pure theory, insufficiently grounded in validating anecdotes from their own practical experience. Even translation theorists who are most actively hostile to the anecdotal roots and ethic of translation studies, like André Lefevere and Lawrence Venuti, find it necessary to slip quick anecdotes from their own translation practice into theoretical works.

3. The emergence of an integrated scholarly field called "translation studies" in the last few decades has been predicated on the methodological repression or suppression of the field's anecdotal origins.
What people usually mean when they say translation "theory" begins with Dryden's preface to Ovid in 1680, or Eugene Nida in the 1940s, or the polysystems school in the 1970s, is that in these watershed periods scholars finally began to overcome the field's reliance on the anecdote, the personal, and the local in favour of the "scientific" or "systematic" depersonalized rhetoric of universal truth. For some writers, "overcoming anecdotalism" seems to be a marker for methodological progress. In the course of attacking the anecdotalism of my own book The Translator's Turn, for example, André Lefèvre cites Barbara Folkart, who "proves in her Le conflit des énonciations (1991) that the kind of research in translation that has come of age can dispense with the anecdote." (The verb "proves," with its aura of scientific method, acts rhetorically to banish any lingering "anecdotal" subjectivity in Folkart's or Lefèvre's desire that this methodological "coming of age" does or will indeed dispense with the anecdote). The ancient and to some extent continuing domination of the anecdote and anecdotal ethic is felt by some scholars in the field to be a restriction or limitation, a millstone around their necks that is an uncomfortable relic from an embarrassing past. If translation studies are ever to earn the respect of scholars in other fields, they argue, it must shake off this fetishistic attachment to the anecdote and become truly scientific. Aslong as translation studies remains grounded in personal stories about "how I translated X," it will be scorned as unscientific, unscholarly, and lacking rigour. In addition, these scholars insist, the anecdote is too narrow, too limited to the experience of individuals, and unable to rise from the local to the global. It is incapable of generating new knowledge through comparison and contrast, or hypotheses and testing.

4. The recent collection of essays edited by Sherry Simon, Culture in Transit: Translating the Literature of Quebec, might be made to serve as a test case for the methodological issues surrounding anecdotalism.

Culture in Transit is insistently anecdotal throughout; indeed, whenever one of Simon's thirteen authors does resist the anecdotal ethic and strives to become systematic (Kathy Mezei), historical (Jane Brierley), or just rhetorically neutral (William Findlay), this resistance continues, easily or uneasily, to be grounded in an anecdotal ethic. Two of the pieces (Linda Gaboriau, Sheila Fischman) are based on interviews, one (Barbara Godard) on a translator's journal. One piece (Suzanne Lotbinière-Harwood) takes us through three different phases of the translator/theorist's personal voice in articulating the problems and joys of translation. There is not a single piece in the 
collection that does not address the writer's own experience of translating specific Quebec authors; and for most of them, that is their main point. If the anti-anecdotalists are right, the book should be a hopeless failure: too local (Quebec-oriented) to enable generalizations to other translation practices, and too subjective, and biased to generate useful scholarly insights from its position amid the fleeting and banal. If the book can be shown to transcend such limitations despite its grounding in anecdotage, then perhaps the teleological model of translation studies "growing out of" anecdotalism is overly simplistic and needs to be rethought.

5. Anecdotes assume explanatory power in theoretical works by exploiting the intrinsic complexity of local, individual experience in ways that complicate or problematize established theoretical assumptions, norms or propositions and thus advance the field.

It is true that some anecdotes are theoretically banal, but anecdotes are not inherently banal. They only become (or remain) banal when they serve no scholarly or theoretical purpose. There are many anecdotal genres, and each has its own way of charging the anecdote with general(izable) interest. In biography and autobiography, for example, the reader may be motivated to read anecdotes from the author's or biographical subject's life because of the subject's celebrity (any story is inherently interesting); because given anecdotes shed important light on the subject's achievements (only carefully selected stories are interesting); or because the author's style is compelling (only well-told stories are interesting).

In theoretical writings, the primary motivation for anecdotalism is the power of local complexity to unsettle or unseat large universalized patterns or paradigms, which are by definition reductive. Anecdotes that do not elicit such complexity, or that do not apply whatever complexity is elicited to the unsettling of established universals, will be banal.

Simon's collection too has examples of such "failures." The opening pages of the first piece, "On Becoming a Translator" by Wayne Grady, tells us how Grady decided to become a translator (he wondered what feux d'artifices might be in English), and how he got early jobs (a friend who was president of Methuen brought English-language rights to a novel by Antonine Maillet home from the Frankfurt book fair). By page 23, however, the fourth page of Grady's essay, he is telling a story about a conference he attended in Norway, where he was asked by a member of the audience: "Do you mean to say that Canadian translators spend all their time translating other Canadians?" (25). While not exactly true, this representation of
Canadian translation practices was close enough to Grady's sense of the truth, and surprising enough to him once he began to reflect on its implications, to be worth noticing and repeating. This is, in fact, almost certainly the insight that makes books like Simon's worthwhile: the Quebec situation is substantially different from most in the world and the complexities of local anecdotes shed enormously productive light on translation everywhere simply by dint of contrast.

Other anecdotal highlights of the book are passages where the various authors harness their anecdotal insights to a complex theoretical imagination:

- Luise von Flotow tells stories about growing up German in English-speaking Canada after World War II, and notices: "The whispers and outright attacks had to be digested; we developed a form of "cannibalistic" translation, I think, ingurgitating the insults and later, as we began to see clear, regurgitating them as disdain for the limited minds of our torturers" (31). Her "recall" of this childhood anecdote is partly structured, no doubt, by theoretical reading about cannibalistic translation in Georges Steiner, Serge Gavronsky, and Lori Chamberlain, as well as perhaps the Brazilian de Campos brothers. Recall, however, is always structured by thought, and the more the anecdote interacts dialectically with complex theoretical ruminations, the better able it will be to give something back.

- $\quad$ Suzanne Lotbinière-Harwood writes: "Francœur was the first and last male poet I translated. During the three years spent on his poetry, I realized with much distress that my translating voice was being distorted into speaking in the masculine. Forced by the poems' stance, by language, by my profession, to play the role of male voyeur. As if the only speaking place available, and the only audience possible, were male-bodied. I become very depressed around meaning. Every word felt shadowed in doubt. Fortunately, the new context then being create by feminism, and by feminists' analyses of, among other things, women's relationship to langage, helped validate the why of my depression and save my sanity. Demonstrating that the personal is, indeed, political" (64). That last line provides the methodological and ideological rationale for telling us how she felt, how close she may have been to mental illness. Anecdotes must not only be trenchant and insightful; they must have some larger application or applicability, in this case political. No translation scholar or translator needs to know about Lotbinière-Harwood's mental state unless 
that same state somehow potentially threatens him or her as well.

- Linda Gaboriau generalizes from experiential anecdotes: "The difficulty of translation lies in capturing the rhythms of the text, in understanding the points at which the dialogue chokes up, then pouring out. This process involves identifying something quite intangible and then trying to communicate those terrible emotional blocks or outbursts" (89). This "is" the difficulty of translation because this is what feels difficult to Gaboriau. She is probably not "right" in any objective or universal sense; any "rightness" is rhetorical, in the impact her pronouncement has on the reader, who is nudged toward a testing of it against her/his own experience.

- Philip Stratford relates his experiential sense that the translator's advantage over the writer, that of being able to turn the page and know what comes next, is actually a disadvantage: "To know what is coming next is the kiss of death for a reader. It interferes with the creative process also. While novelists and poets do not usually write completely blind, they do rely heavily on a sense of discovery, of advancing into the unknown as they pursue their subject and draw their readers along with them. The challenge for the translator [...] is to find ways to reproduce this excitement, this creative blindness, this sense of discovery, in the translation process. The translator must, like an actor stimulating spontaneity, use tricks and certain studied techniques to create an illusion of moving into the unknown. To cultivate creative blindness one should never read a text one is going to translate too carefully at first, and once only. It helps to have a short memory" (97). No doubt some translators will react with shock and revulsion to this view. As it happens, it fits my experience exactly, but until I read Stratford I thought of my attitudes in this area as idiosyncratic - certainly nothing to generalize from. Generalization from such local insights continues to be problematic, but the problems inherent in such generalization also continue to be productive for the field.

- Betty Bednarski addresses the complexity of "assimilation," somewhat simplistically attacked by foreignists like Antoine Berman and Lawrence Venuti: "Assimilation is, of course, fundamentally ambiguous, a phenomenon that can be perceived in radically different ways, like the forms we see as alternately concave and convex, according to the conditions of their viewing. In the textual conditions imposed by most writing in joual, that assimilation, however amusing, will inevitably take on the appearance of an infiltration, and therefore of a defeat" (116).

Like systematic theorizing, anecdotal theorizing is only valuable to the scholarly community if it generates new knowledge, new understanding.

6. Systematic or scientific thinking is no less susceptible to banality than anecdotal thinking.

Systematizing observations does not protect them against banality as systematization is no more intrinsically productive for a field than storytelling. It may be rhetorically more effective for readers who have been trained to think systematically, just as anecdotes are rhetorically more effective for readers who remain suspicious of global systematizing. However, even for systematizing readers some systematic thinking will be hopeless banal, either because the system is poorly constructed or because it has nothing new or transformative to say.

Consider, for example, the piece by Kathy Mezei, the collection's primary systematization of the field. She too tells a single, utterly banal anecdote which seems to confirm the anti-anecdotal prejudice. This single paragraph might indeed be construed as Mezei's unfortunate and damaging forced surrender to the anecdotal ethic that still dominates translation studies. Significantly, however, the anecdote in question remains banal not because it is anecdotal, but because it lacks the kind of dramatic tension and complexity that can complicate a systematic understanding. It is a systematic insight, a perceived comparison or contrast, that could have been just as persuasively presented without anecdotal trappings. While involved in two translation projects (showing that she is indeed a translator, and thus someone to be listened to), as well as a bibliography project, M ezei writes, "I noticed that many of the English translations I read participated in a subtle subversion of Quebec culture," in that many of the Quebec texts used English words "as a highly symbolic signifier" that "was rarely acknowledged in the target or re ceptor text" (136). Even if this were not the central issue of Quebecois translation theory and of this entire book, telling an anecdote just to say she noticed it would be banal. Her anecdote gives us no experiential complexities, no tensions, no insight into the conflicted subjectivity of a practicing translator; she was doing something practical related to translation and she noticed something.

The remainder of M ezei's article constitutes a systematization of this initial insight. And certainly, systematic thinkers do always gain their insights in specific situations - they would not be human if they didn't. Whether it will be productive 
to present the germ of those insights anecdotally, however, will be controlled by several factors, uppermost among which would be generic norms (are Quebec translation theorists expected to couch their insights anecdotally?) and the heuristic power of an anecdotal account, its complicating effect on later systematization.

The taxonomy that follows in Mezei's article, of "modes" by which Quebecois texts are translated into English, provides a useful instance of the banality to which systematic thinking is subject. For one thing, the taxonomy is systematic in appearance only: I found it almost impossible to distinguish any one of the three main categories from any other, or any of the subcategories from either the other subcategories or the main categories. Indeed, I found it difficult to determine just what she was attempting to taxonomize. She refers several times to "this mode," suggesting that her three main categories do indeed refer to different approaches to the problems of translating Quebecois texts into English. But the first category is described as dealing with "some examples of the political use of English" (139), which does not sound much like a translational mode, and which almost certainly applies equally well to the other two. The second says "A second mode, this time of mistranslating English, also has cultural consequences" (142), and the third, "Finally, the mis- or nontranslation of English has another consequence, less momentous than the previous two, but nevertheless significant in terms of the French author's narrative strategies" (144).

Taken together, these descriptions suggest that the first "mode" is nontranslation and the second mistranslation; but what is the third? It looks like more examples of what we've al ready seen in the first and second. "Nontranslation" seems like a strange category for the examples in the first mode: in (i), for example, the playwright Michel Tremblay has a Quebecois housewife with pretensions use the English word "cheap," and his English translator translates that as "cheap." If this is "nontranslation," would the desired alternative to it be "translation"? If so, into what language? Mezei seems to be suggesting that the translator should have marked "cheap" in some way in English as in the original; but this is not really a translation vs. nontranslation situation. In (ii) she considers translators who italicize English words that were in English in the French original; this too is nontranslation in a strict sense, but the term seems peripheral to the problem (and the term "nontranslation" isn't in fact even mentioned until category 3). In (iii) she deals with the problems of translating parodic texts; the only examples of a "mode" of translation, however, involve the transliteration of joual words like Le Tchiffe as the Chief, Biouti Rose as
Beauty Rose. Is this still nontranslation? In (iv) the submode becomes the creation of an equivalent street dialect in English, which I'm pretty sure entails translation - though still not a type she likes. Subcategory (v) isn't a new submode at all, just a problematic comment on all this, quoted from Brandon Conron. Finally, (vi) is an example of intralingual translation. In all, an odd and certainly unsystematic collection of instances - instances of what, exactly, remains unclear.

Under (2), the "mistranslations" include changing a list of names (ii) and the exclusion of many poems from the Quiet Revolution in an anthology (iii), of which she says: "Although my final example in this mode is not one of mistranslating English, it again indicates how translations can distort the transmission of translated authors" (143). Why then include it under mistranslations? The question of whether a list of names is ever "translated," thus becoming susceptible to "mistranslation," is an interesting one that Mezei begs. Most linguistic theorists of translation would argue that proper names have no semantic content and thus are not, or should not be, translated. Clearly, however, the political and cultural significance of a list of names like "Gertrude Stein, M adeline de Verchères, and Emma Goldman" poses a more complicated translational problem than either linguistic theorists or Kathy M ezei are willing to explore.

\section{Systematic thinking is no more immune to} begged questions than anecdotal thinking.

Our assumptions and prejudices are, after all, as $\mathrm{H}$ ans-Georg Gadamer reminds us, precisely what makes any form of understanding possible: you have to stand somewhere in order to think or say anything. Systematic thinkers make a virtue of examining all assumptions and prejudices, and scorn anecdotal thinkers for failing to do so. However, this collection shows that such scorn may in fact be misplaced and hypocritical.

Betty Bednarski, for example, tells us anecdotally that she imagines a certain type of reader for her translations: one who is more or less monolingual in English and unable to read French phonetic and graphic conventions very well. Hence, "For the reader who knows little or nothing, Ferron's original spelling could pose serious problems" (121). Among the assumptions underlying this statement: (1) there really are readers like this in the world; (2) they will one day pick up the translation and read it if their linguistic limitations are accommodated, and put it down if they are not; (3) the existence and behavior of these readers is known to, and influences editorial decisions made by, members of the publisher's editorial staff; (4) imagining readers of this sort, and doing it realistically, is therefore essential to successful translation. 
But begged questions or uncritical assumptions also exist in the work of the collection's systematizer, Kathy M ezei:

- " $\quad[M]$ ]uch of the parody at the semantic level becomes lost in the English version" (140). Assumptions: (1) semantic loss in translation is avoidable; (2) semantic loss in translation is bad, and should be avoided; (3) semantic gain is irrelevant and need not to be mentioned.

- "What and how certain texts are translated, what is omitted, what is altered, and what is foregrounded can give us a biased and modified impression of Quebec culture. Quebec becomes not what it is, but what we wish it to be" (142). Assumptions: (1) an unbiased, unmodified, objective representation of Q uebec is possible; (2) translators should strive to present such a representation; (3) translators who fail to present one, who impose their own subjective interpretations on it, are culpable.

- "Therefore one is inevitably creating and not just translating meaning" (143). Assumptions: (1) meaning exists in a stable objective form; (2) it can be transferred intact from one language or culture to another; (3) this transfer is the ideal for translation; (4) this ideal sets an upper limit ("just translating") for translation; (5) translators who exceed this limit and "create" meaning are culpable; (6) it is possible not to create meaning.

- " $[T]$ he alteration changes this emphasis, creating cultural difference" (143). Assumptions: (1) cultural difference is good when it is stable and objective (that between Quebecois and English Canadian culture, for example); (2) translation should respect and reflect such existing differences; (3) cultural difference is bad when it is fluctuating and subjective (introduced by the translator); (4) translators who introduce such alterations are culpable; (5) the relative stability of cultural difference can be controlled.

8. Anecdotal and systematic approaches to translation have different but complementary strengths, and ideally should work together, dialectically.

In the rhetorical tradition of the West, systematic thinking must be simple, concise, and elegant (Occam's Razor says that the simpler explanation is likely to be the truer); anecdotal thinking should be realistic, novelistic, authenticated by a subjective narrative voice, true to the complexity and inconclusiveness of experienced reality. Hence the importance of using both. A good anecdote will "remember" complexities that a mediocre system represses; a good system will not only help people make sense of their anecdotes but will direct them to other experiences that they had never before considered, never before "anecdotalized" or narrativized. A system that loses touch with the wealth of anecdotal material from which it was reduced becomes reductive; an anecdote without systematic awareness or reflection becomes dumb.

A good example of the fruitfulness of a lively dialectic between anecdotal and systematic thinking is the exchange in Simon's collection between Kathy Mezei and Betty Bednarski. Since Bednarski's piece is printed first, and she explores at such complex anecdotal length the constraints on successful translation, M ezei's systematic treatment of the same ground (immediately following Bednarski's in the collection) seems reductive by comparison. Since Bednarski has just been telling us (125) how she has had to fight with editors for every foreignizing usage (such as Mezei advocates), it seems simplistic and "theoretical" (in the worst sense of the word) of Mezei to refer to "Sheila Fischman's translation of [Hubert Aquin's] Neige noire as Hamlet's Twin, which is a deliberate and inappropriate anglicization of Aquin and ignores the signification of 'snow', a dominant image of Quebec literature, and of 'black'" (135). Ten pages later (145), M ezei belatedly remembers that translators are not entirely in control of such things; but here at the beginning of her essay she blames Fischman for a decision that was almost certainly made by an editor. This seems an excellent example of the anecdote remembering what the system forgets: Bednarski's anecdotal piece is rich with the obstructions the translator must somehow hurdle in order to do an even halfway passable translation. But it should also be remembered that Mezei published her article in 1988; Bednarski has the luxury of responding to it. Whatever reductiveness $M$ ezei built into her systematic treatment of Quebec-English translation, Bednarski was able to test it at her leisure in her own translation practice and reflections thereupon, first in her book Autour de Ferron (1989), later in her English rethinking and rewriting of the second chapter of that book for Simon's collection.

9. The differences between anecdotal and systematic thinking will be perceived and val orized differently by different readers.

Some readers, for example, will say that Kathy Mezei's article is simply badly reasoned and/ or badly written, and thus inappropriate as an example of the problems intrinsic in systematic thought. The problems in her writing aren't intrinsic to systematic thought (and let me emphasize that I have not suggested that they are); they're only an example of bad systematic thought. These readers will probably want to thematize the banal- 
ity of the first few pages of Wayne Grady's piece as intrinsic to anecdotal thinking, while avoiding the extension of that judgment from Kathy Mezei's article to all systematic thinking.

Other readers will find Grady's opening fascinating, not banal; or will read M ezei's taxonomy as incisive, not muddled.

Still other readers will want to minimize the methodological differences between, say, Bednarski and Mezei (they're both hybrids, mixtures of systematic and anecdotal approaches); or will insist that the differences are other than what I claim they are.

I quoted above - to shift, by way of conclusion, from the systematic to the anecdotal - an attack on the anecdotalism of my work, which in the eye of the reviewer made my book purely subjective (limited to my own experience, without application beyond that experience) and based in utter ignorance of the recent history of the field and its attempts to overcome the harmful legacy of anecdotalism. From my point of view this attack is a symptom of the harmful legacy of uncritical systematizing: if you have to exclude all middles, clean up all messes by sweping them under one or the other side of a dualism, then the kind of dialectic I build between anecdotes and systematic thinking will seem like ignorant subjective anecdotalism pure and simple. The ignorance, subjectivity, and unsystematic nature of these attacks amaze me - can readers advocating strict logical rigour really be reading my work so badly and incompletely? and incline me slightly to defend anecdotalism ... even though I too have sat at conferences thinking if I have to listen to one more translator telling me how she translated this or that difficult passage and why, I'm going to scream; even though I too have shaken my head in disgust at a whole collections of essays that can say nothing more, over and over, than "this is how I did it."

But maybe all that means is that the desideratum, at least for me, is a smart anecdotalism, or a systems approach that is soaked in experiential detail. It isn't enough to tell the stories without thinking about them, without letting complex theoretical perspective derail your understanding of what happened and why; and it is no solution to dumb anecdotalism either to exclude the personal, the experiential, the anecdotal entirely and create a bland depersonalized sham of "objectivity" or "neutrality." Let's not overthrow the anecdotal tradition of translation studies; let's just smarten it up. Like earlier work by Simon, Bednarski, LotbinièreHarwood, Barbara Godard, and the other writers in this collection, Culture in Transit is an important step in that direction.

Dougl as Robinson

University of Mississippi, University City, United States 